Again the men failed to notice that many of the observations they made could be used to check others previously made, and prove their falsity. When this girl was lying down, the hip movements were extremely restricted, and the hip was slightly adducted. When she walked she lurched right over, and it was obvious that the hip-joint was moving over a wide range and into nearly full abduction. Lying down the muscles were in spasm; walking, the gait spoke of a flail or paralytic hip. A lurching gait indicates an inefficient gluteus medius, either because it is paralysed, as in poliomyelitis, or because its leverage is gone, as in congenital dislocation of the hip. When Trendelenburg's test was applied in this patient (standing on one leg), the right side of the pelvis was instinctively raised, showing that the hip abductors on the left were normal. Other muscles could be cross-checked in similar manner. Thus, when asked to extend the hip there was no contraction of gluteus maximus; but if laid on her face and told to raise her head, it contracted normally.

The treatment belongs to psychotherapy. Our friend, having reached Guy's, patronizes many departments and comes back from each with a fresh splint. I am,

Treatment. however, averse from removing these gadgets, as I do not wish to do anything to prejudice the curative treatment that will be undertaken when she is admitted to the medical wards under my colleague Dr. Gillespie.

\title{
SOME REMARKS ON THE ROUTINE OF EXAMINATION OF A PATIENT.
}

\section{By DAVID LEVI, M.S., F.R.C.S.}

MORE store is laid by the majority of the Examiners at the Fellowship Examination upon a correct physical examination and the logical marshalling of facts so gleaned than upon a spot diagnosis which is often nothing more than a guess. Patients at the examination hall fall into two groups. In the first group the diagnosis is obscure and a routine examination of the patient must be made. Many of the "long" cases may be so classed. The "short" cases often fall into the second group, the group in which the diagnosis is obvious. The object of the examination of these patients should be to confirm rapidly the preformed impression and the examination should then resolve itself into a search for the common complications that may be associated with the lesion found.

Recently a patient with a tumour in the neck was shown to candidates at the London Temperance Hospital. Most men diagnosed an adenoma of the thyroid. Many could not, however, when asked, say whether it was solid or cystic, and a still greater number were unable to say whether there were toxic signs present or not. If the patient seen, however, falls into the second group and the diagnosis is not obvious to the candidate, many men fail-because of the haphazard, happy-go-lucky way in which they examine the patient-before they have even been asked a single question by the examiner. A patient should be examined in a routine logical manner. Each part of one's examination of the patient should be carried out rapidly, but in a logical orderly sequence. For example, when shown the patient with the tumour of the neck, many candidates 
asked the patient to swallow and when asked for a diagnosis, said that the patient had an adenoma of the thyroid. Had, however, the patient been examined in a routine manner and been asked what she was complaining of (the history) before any examination was commenced, the examinee would have elicited that the patient sought advice on account of hoarseness of the voice, a fact of momentous importance in arriving at the correct diagnosis of the lesion.

It is of little use to attempt to assume the cloak of orderly routine method during the examination if one is habitually slovenly when dealing with patients. Routine examination must be practised and used on all occasions when one has cause to examine patients. For there are many things which may occupy the mind during the visit to Queen Square, and the routine examination of the patient should, by then, have become a conditioned reflex. Conditioned reflex because a different series of reflexes should be stimulated in the examinee when different diseased systems of a prospective patient are presented to him. Thus a diseased joint should automatically call for the following sequence of thought:-

(I) A history; (2) inspection of diseased and sound side; (3) palpation; (4) movements, sound side first ; (5) measurements ; (6.) special tests (i.e., for tabes); (7) and the request for an X-ray examination.

Similarly when confronted by a patient with urinary symptoms an orderly method of investigation of such a patient should reflexly jump to mind.

It is admittedly a gift to be able to anticipate the question that one is to be asked at an examination, but it is not an impossible art to lead the examiner's questions in one particular desired direction. There are many ways of doing this. Very often the addition of a word will suffice. It is quite a task to think of questions to ask candidates, and many examiners, especially late in the afternoon, will unconsciously take the lead from the answers tended by the examinee.

The assumption and presentation of an American classification of a diseased organ, i.e., goitres, is to he strongly deprecated unless the candidate previously reveals that he is aware of the more usual British classification.

The fact that America is several thousand miles away anci that goitre may differ in the two countries must not be lost sight of.

The last stumbling-block to the candidates was in giving the detailed steps of the operation for enucleation of an adenoma. Only one man described the operation correctly. Such points as where to cut the infra-hyoid muscles, and how to remove the adenoma from the gland, produced many and varied answers.

\section{SWELLING IN RIGHT FOREARM.}

BY R. LESTER WILLIAMS, F.R.c.s.

THE patient is a woman, aged $5^{\mathrm{I}}$, complaining of a swelling of the right forearm. She first noticed a general swelling of the flexor surface of the right foreHistory. arm in I9I8. The swelling gradually increased in size until it extended along the whole of the flexor surface of the forearm from just below the 